\title{
Poorer outcomes among cancer patients diagnosed with Clostridium difficile infections in United States community hospitals
}

\author{
Andrew Delgado ${ }^{1,2}$, Ivan A. Reveles ${ }^{1,2,3}$, Felicia T. Cabello ${ }^{1,2}$ and Kelly R. Reveles ${ }^{1,2^{*}}$
}

\begin{abstract}
Background: Cancer predisposes patients to Clostridium difficile infection (CDI) due to health care exposures and medications that disrupt the gut microbiota or reduce immune response. Despite this association, the national rate of CDI among cancer patients is unknown. Furthermore, it is unclear how CDI affects clinical outcomes in cancer. The objective of this study was to describe CDI incidence and health outcomes nationally among cancer patients in the United States (U.S.).

Methods: Data for this study were obtained from the U.S. National Hospital Discharge Surveys from 2001 to 2010. Eligible patients included those at least 18 years old with a discharge diagnosis of cancer (ICD-9-CM codes 140-165.X, 170-176.X, 179-189.X, 190-209.XX). CDI was identified using ICD-9-CM code 008.45. Data weights were applied to sampled patients to provide national estimates. CDI incidence was calculated as CDI discharges per 1000 total cancer discharges. The in-hospital mortality rate and hospital length of stay (LOS) were compared between cancer patients with and without CDI using bivariable analyses.

Results: A total of 30,244,426 cancer discharges were included for analysis. The overall incidence of CDI was 8.6 per 1000 cancer discharges. CDI incidence increased over the study period, peaking in 2008 (17.2 per 1000 cancer discharges). Compared to patients without CDI, patients with CDI had significantly higher mortality $(9.4 \%$ vs. $7.5 \%$, $p<0.0001)$ and longer median LOS (9 days vs. 4 days, $p<0.0001$ ).
\end{abstract}

Conclusions: CDI incidence is increasing nationally among cancer patients admitted to U.S. community hospitals. CDI was associated with significantly increased mortality and hospital LOS.

Keywords: Clostridium Difficile, Cancer, Epidemiology, Mortality

\section{Background}

Clostridium difficile is the most common pathogen contributing to healthcare-associated infections [1]. This Gram-positive, anaerobic bacterium can colonize the human gut, typically following health care contact and exposure to agents that disrupt the normal gut microbiota, like antibiotics. Patients may then develop a toxin-

\footnotetext{
* Correspondence: kdaniels46@utexas.edu

${ }^{1}$ College of Pharmacy, The University of Texas at Austin, 2409 University Avenue, A1900, Austin, TX 78712, USA

${ }^{2}$ Pharmacotherapy Education and Research Center, The University of Texas Health Science Center at San Antonio, 7703 Floyd Curl Drive, MC-6220, San Antonio, TX 78229, USA

Full list of author information is available at the end of the article
}

mediated intestinal disease, Clostridium difficile infection (CDI). CDI results in frequent diarrhea, but may also progress to megacolon, ileus, sepsis, or even death [2]. National epidemiological investigations have demonstrated significant increases in CDI incidence in the United States (U.S.) in recent years. A recent study found that the rate of CDI in U.S. community hospitals increased two-fold between 2001 and 2010 [3].

Cancer has been previously found to be associated with the development of CDI. One study found that the rate of hospital-onset CDI was twice as high among cancer patients as compared to all other inpatients [4]. This association is likely due to a number of factors. First, 
cancer patients might have a greater degree of exposure to $C$. difficile due to frequent or prolonged hospitalizations. Second, immunosuppression from the disease or drug therapy could predispose cancer patients to develop clinical infection, rather than colonization. Furthermore, prior studies have shown that immunosuppressed patients who develop CDI are at higher risk for poor clinical outcomes $[5,6]$. Lastly, cancer patients are frequently exposed to medications and other factors that can alter the gut microbiota, including certain chemotherapeutic agents, antibiotics, gastric acid suppressing medications, and manipulation of the gastrointestinal tract (e.g., enteral feedings). As gut microbiota play a role in preventing $C$. difficile colonization and virulence, these alterations can lead to CDI [7].

Despite this association, the national rate of $\mathrm{CDI}$ among cancer patients is unknown. Furthermore, it is unclear how CDI affects clinical outcomes in cancer. Therefore, the objectives of this study were to describe longitudinal trends in CDI incidence among hospitalized cancer patients in the U.S., describe trends in mortality and inpatient length of stay (LOS) in cancer patients with CDI, and compare outcomes in cancer patients with and without CDI.

\section{Methods}

\section{Data source}

The data source for this study was the U.S. National Hospital Discharge Surveys (NHDS) from 2001 to 2010. These surveys contain a national probability sample representative of the U.S. population discharged from community hospitals annually. Staff from the participating hospital, U.S. Census Bureau, or National Center for Health Statistics collected NHDS survey data manually or automatically, including International Classification of Diseases, Ninth Revision, Clinical Modification (ICD9-CM) codes for diagnoses and procedures. Sampling and collection methods allow the user to apply data weights to hospital discharge data to derive national estimates, as previously described $[3,8]$. The datasets are publically available through the U.S. Centers for Disease Control and Prevention and contain no patient identifying information; therefore, this study was considered non-human subjects research by the Institutional Review Board of the University of Texas Health Science Center at San Antonio.

\section{Study design}

This was a retrospective analysis of patients $\geq 18$ years old with a principal or secondary ICD-9-CM discharge diagnosis of cancer (140-165.X, 170-176.X, 179-189.X, 190-209.XX). Blood cancers were identified by codes 200-208.XX, while all other patients were considered to have solid cancers. Patients with a principal or secondary diagnosis code for CDI (ICD-9-CM code 008.45) were identified, and formed subgroups for analysis. Principal CDI refers to patients with an ICD-9-CM code in the first position, which generally denotes the primary reason for hospitalization. Secondary CDI refers to patients having an ICD-9-CM code in any other position, and represents a contributory diagnosis not primarily responsible for hospitalization. Diagnostic procedures vary by facility, and are not indicated in NHDS survey data.

Patient baseline characteristics included sex (male or female), race (categorized as white, black or other), geographic region as defined by the U.S. Census Bureau, hospital size (6-99 beds, 100-199 beds, 200-299 beds, $300-499$ beds, or $\geq 500$ beds), principal payment source (private, Medicare, Medicaid, self-pay, or other), and admission type (emergency, urgent, elective), as previously described [3, 8]. Mortality was defined as all-cause, inhospital mortality and was derived from the "discharge status" item of the NHDS. Length of stay was calculated using the "days of care" item of the NHDS.

\section{Data and statistical analyses}

Annual and total CDI incidence rates were determined by dividing CDI discharges by cancer discharges. Rates were presented as principal, secondary, and overall CDI discharges per 1000 total adult cancer discharges. We also characterized CDI incidence for blood and solid cancers. Patient characteristics were described as median (interquartile range) for continuous quantitative variables and counts (percentages) for nominal categorical variables.

Baseline characteristics were compared between adult cancer patients with or without a CDI diagnosis using bivariable analysis (Wilcoxon rank sum test for continuous variables and chi-square test for categorical variables). An alpha level $<0.0001$ was used to determine statistical significance due to the large sample size. Independent predictors of mortality and LOS were identified using multivariable logistic and linear regression, respectively, and the following covariates: age, gender, race, marital status, season, geographic region, and number of hospital beds. Odds ratios (OR) and 95\% confidence intervals $(\mathrm{CI})$ were reported for the model.

\section{Results}

\section{Baseline characteristics}

Table 1 provides an overview of the study population. These data represent approximately 30,244,426 cancer discharges from U.S. hospitals from 2001 to 2010. CDI was present in $260,219(0.9 \%)$ cancer patients. Of these, principal and secondary CDI occurred in 64,933 (25\%) and 195,286 (75\%) patients, respectively.

Cancer patients with and without CDI differed significantly in age, sex, race, geographic region, hospital 
Table 1 Patient demographics $(n=30,244,426)$

\begin{tabular}{|c|c|c|c|}
\hline Demographic & $\begin{array}{l}\text { No CDI } \\
(n=29,984,207)\end{array}$ & $\begin{array}{l}\text { CDI } \\
(n=260,219)\end{array}$ & $P$ value $^{a}$ \\
\hline Age $(y)$, median (IQR) & $69(57-78)$ & $71(61-78)$ & $<0.0001$ \\
\hline \multicolumn{3}{|l|}{ Sex $\%$} & $<0.0001$ \\
\hline Male & 50.2 & 51.3 & \\
\hline Female & 49.8 & 48.7 & \\
\hline \multicolumn{3}{|l|}{ Race, \% } & $<0.0001$ \\
\hline White & 81.5 & 87.4 & \\
\hline Black & 14.4 & 7.6 & \\
\hline Other & 4.1 & 5.0 & \\
\hline \multicolumn{3}{|l|}{ Geographic Region, \% } & $<0.0001$ \\
\hline Midwest & 26.1 & 24.2 & \\
\hline Northeast & 22.5 & 26.4 & \\
\hline South & 37.0 & 32.0 & \\
\hline West & 14.4 & 17.4 & \\
\hline \multicolumn{3}{|l|}{ Hospital Size, \% } & $<0.0001$ \\
\hline $6-99$ & 18.1 & 11.1 & \\
\hline 100-199 & 22.6 & 21.2 & \\
\hline $200-299$ & 20.0 & 25.3 & \\
\hline $300-499$ & 23.4 & 24.9 & \\
\hline Over 500 & 15.8 & 17.5 & \\
\hline \multicolumn{3}{|c|}{ Principal payment source, \% } & $<0.0001$ \\
\hline Medicare & 54.0 & 60.6 & \\
\hline Medicaid & 8.0 & 5.6 & \\
\hline Private & 32.5 & 31.6 & \\
\hline Self-pay & 2.6 & 0.7 & \\
\hline Other & 3.0 & 1.4 & \\
\hline \multicolumn{3}{|l|}{ Admission type, $\%$} & $<0.0001$ \\
\hline Emergency & 43.4 & 55.0 & \\
\hline Urgent & 22.1 & 28.0 & \\
\hline Elective & 34.5 & 17.0 & \\
\hline
\end{tabular}

IQR interquartile range, CDI Clostridium difficile infection

${ }^{\text {ap }}$ values represent comparisons between $\mathrm{CDI}$ and no $\mathrm{CDI}$ diagnosis groups

size, principal payment source, and admission type. Patients with CDI were more likely to be older (median age 71 vs. 69 years; $p<0.0001)$, male $(51.3 \%$ vs. $50.2 \%$; $p<0.0001)$, residents of the Northeast region $(26.4 \%$ vs. $22.5 \% ; p<0.0001)$, and Medicare users $(60.6 \%$ vs. $54.0 \%$; $p<0.0001)$. CDI patients' admission type was also more often emergency or urgent ( $55.0 \%$ vs. $43.4 \%$ and $28.0 \%$ vs. $22.1 \%$, respectively).

\section{CDI incidence}

From 2001 to 2010, the overall CDI incidence was 8.6 discharges per 1000 adult cancer discharges. The incidence increased from 6.8 per 1000 cancer discharges in 2001 to 12.8 in 2010 (Fig. 1). Incidence peaked in 2008
(17.2 per 1000 cancer discharges). Principal CDI also increased during the study period, rising from 1.8 per 1000 cancer discharges in 2001 to 4.1 in 2010. Secondary CDI incidence increased from 5.1 per 1000 cancer discharges in 2001 to 8.7 in 2010. The incidence of CDI among blood cancers patients (17.3 per 1000 blood cancer discharges) was higher than that of solid cancers (6.8 per 1000 solid cancer discharges).

\section{Mortality}

Death occurred in approximately $7.4 \%$ of cancer patients during the study period, representing 2,228,061 adult deaths. The mortality rate was significantly higher for cancer patients with CDI compared to without CDI (9.3\% vs. $7.4 \%, p<0.0001)$. This trend was persisted over the study period (Fig. 2). Mortality for those with CDI was only lower than those without in 2002 and 2009. Mortality among cancer patients without CDI was relatively stable across the study period, dropping from $8 \%$ in 2001 to $6 \%$ in 2005 and remaining at this level until 2010. In the multivariable model, CDI independently predicted in-hospital mortality (OR 1.03; 95\% CI 1.011.04), albeit to a small degree.

\section{Hospital LOS}

Overall median (interquartile range) LOS for cancer patients was 4 (2-8) days. The median LOS was significantly longer for cancer patients with CDI compared to without CDI (9 days vs. 4 days, $p<0.0001$ ). Median LOS for cancer patients with CDI dropped slightly from 11 days in 2001 to 8 days in 2010, peaking at 13 days in 2003 (Fig. 3). Median LOS for cancer patients without CDI remained comparatively lower and relatively consistent throughout the study, with 4 days in all study years except 2003 (5 days). Among CDI patients, median hospital LOS was longer for blood cancers compared to solid cancers. CDI independently predicted increased hospital LOS (OR 4.16; 95\% CI 4.12-4.20).

\section{Discussion}

This study documents the national epidemiology of CDI among cancer patients discharged from U.S. community hospitals over a 10 -year period. We found that CDI incidence increased among cancer patients from 2001 to 2010. Furthermore, cancer patients with CDI are at greater risk for mortality and a longer hospital stay.

The rates of CDI among cancer patients found here are relatively large compared to the general population of U.S. hospitalized adults. In a study using the complete NHDS survey data sample, Reveles et al. [9] found that CDI incidence estimates in the general population of U.S. hospitalized adults grew from 4.5 to 8.2 CDI discharges per 1000 total discharges between 2001 and 2010. In parallel with the cancer population, overall CDI 


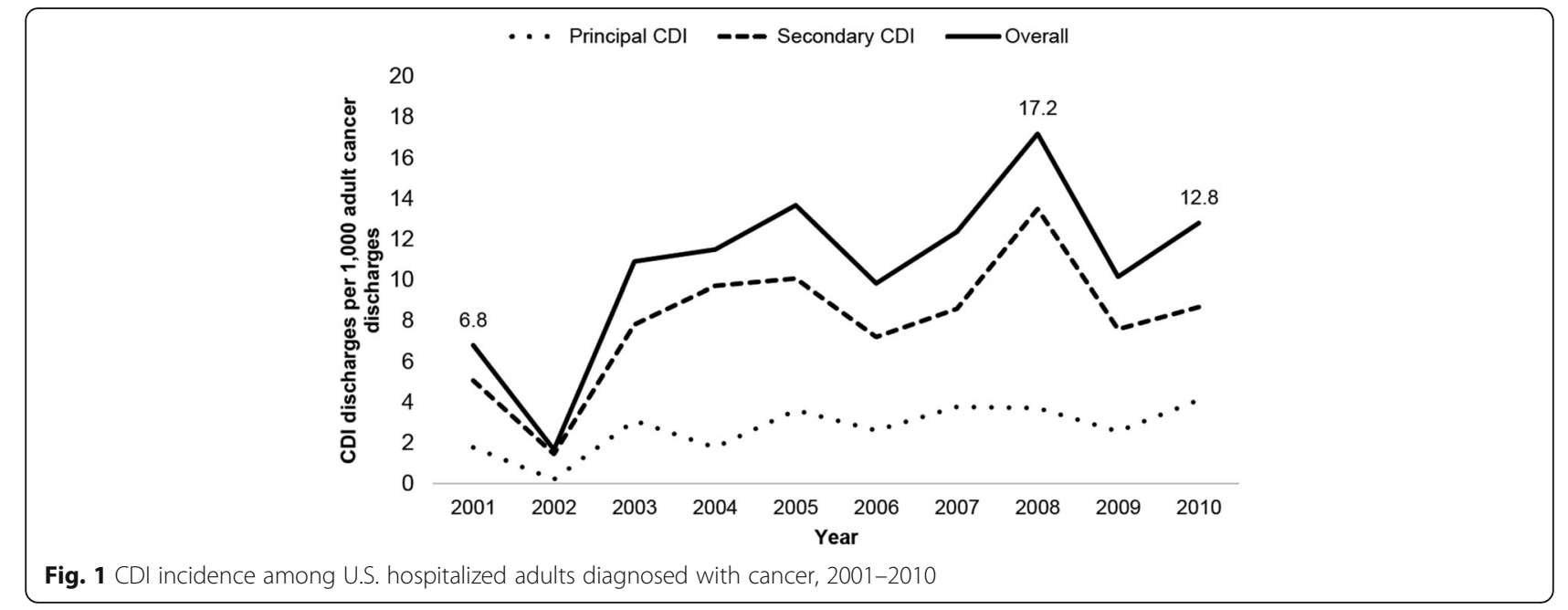

incidence was found to peak in 2008. In an analysis of data from the Healthcare Cost and Utilization Project, Lucado et al. [10] found that between 2000 and 2008, the U.S. saw a 2.5 -fold increase in the number of hospitalizations with any CDI discharge diagnosis. The number of hospital stays stabilized between 2008 and 2009, however. In Canada, reports of CDI epidemics were found to occur around the same period [11-14], with mortality increasing drastically between 1997 and 2005 . And although limited information on the increased incidence of CDI is available across Europe, a network of laboratories in 34 European countries estimated a CDI incidence of 4.1 per 10,000 patient-days per hospital (range 0.0-36.3) in 2008 [15, 16].

The rise of CDI has been partially credited to the spread of the hypervirulent strain of $C$. difficile categorized as North American pulsed-field Type 1, restriction enzyme analysis type $\mathrm{BI}$, and PCR ribotype 027 (NAP1/ $\mathrm{BI} / 027)$. By 2008, CDIs due to the NAP1/BI/027 strain were reported in 40 U.S. states and across Canada, becoming endemic in some North American healthcare settings [17]. In a survey evaluating the spread of ribotype 027 in Europe, this $C$. difficile strain had been found in 16 European countries by 2008 [18]. This same year, Bauer et al. estimated a $5 \%$ prevalence of ribotype 027 across 34 European countries [16]. More recently, the emergence of the ribotype 078 has been associated with disease in younger patients more frequently prescribed fluoroquinolones and with communityassociated or indeterminate CDI, as compared to ribotype 027 patients in the Netherlands [19].

Few prior studies have evaluated the rate of CDI in cancer. Kamboj et al. [4] conducted a survey of 11 U.S. cancer centers, aiming to determine the rate of hospitalonset CDI (HO-CDI) in hematopoietic stem cell transplant (HSCT) and cancer patients. Centers using polymerase chain reaction (PCR) as a detection method were found to have a higher median HO-CDI rate compared to those using enzyme immunoassay ( 1.72 vs. 0.9 per 1000 patient days, respectively), although both rates were higher than those reported for U.S. patients overall. A retrospective review of leukemia patients revealed that CDI occurred in $7 \%$ of all cycles of myelosuppressive chemotherapy. Lastly, an analysis of 134 patients found

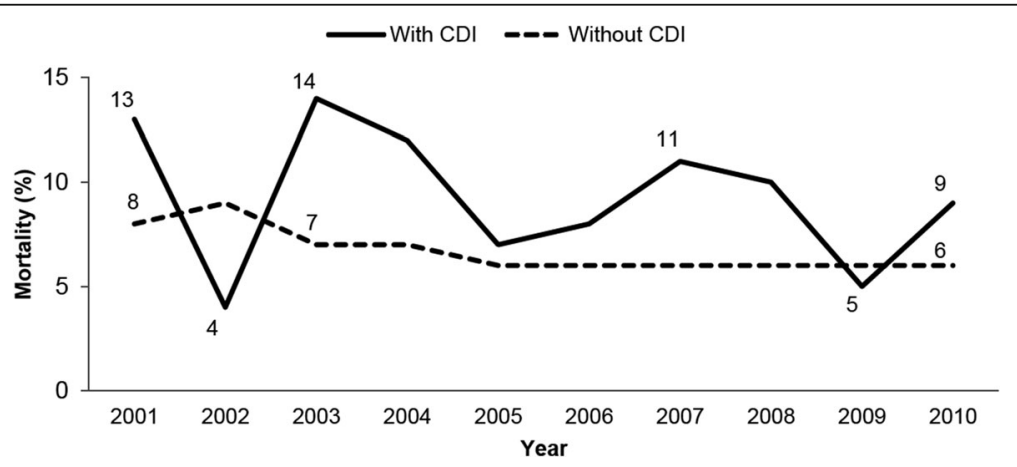

Fig. 2 Mortality among U.S. hospitalized adults diagnosed with cancer with and without CDI, 2001-2010 


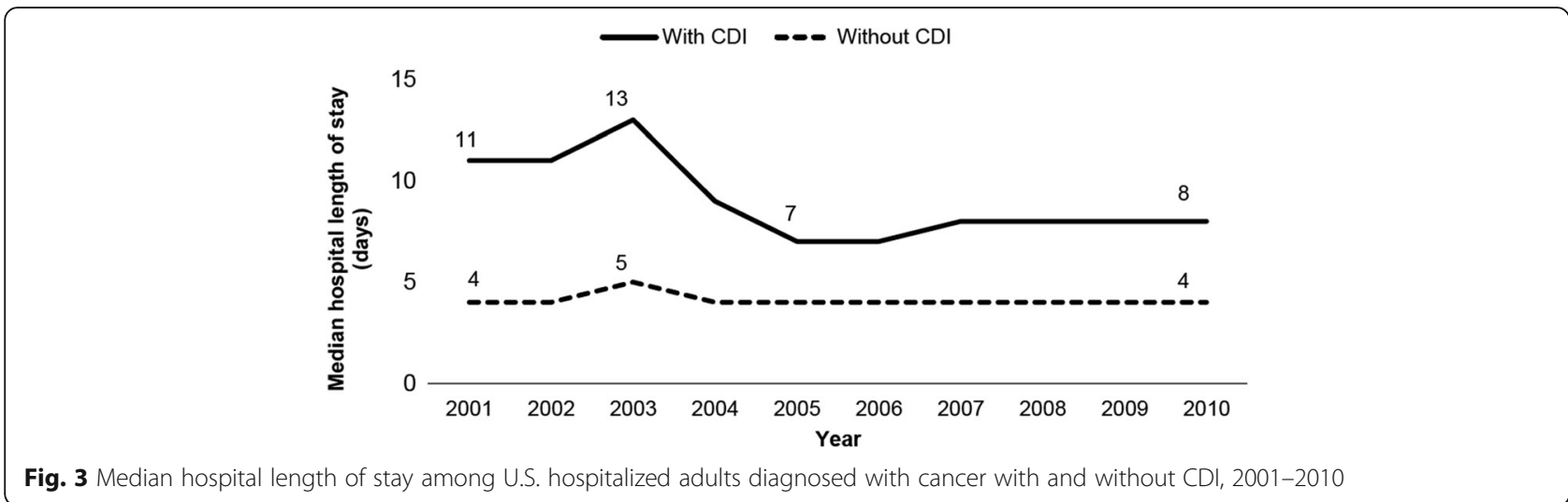

that CDI occurred in $18 \%$ of patients with acute myeloid leukemia and in $9 \%$ of all treatment courses [20,21].

Prior studies have demonstrated less favorable health outcomes among cancer patients who develop CDI compared to those who do not. In a retrospective analysis of 186 U.S. hospitals, Campbell et al. [22] found that highrisk patients suffering from HO-CDI, including those with cancer, have significantly longer LOS compared to non-CDI controls. Similarly, a retrospective cohort study found that CDI inpatients receiving chemotherapy for hematologic malignancies had greater mean length of stay compared to similar patients without malignancies. This increase in stay was largely attributed to cancerrelated care, as the cancer patients often required neutropenia management, total parenteral nutrition, or pain control [23]. In a study of 5594 adult patients receiving cancer treatment with CDI, CDI-related mortality was $19.7 \%$ [24]. This is greater than the 9.1-16.3\% mortality reported by others, perhaps due to differences in duration of neutropenia or dissimilarities in study populations $[25,26]$. Neutropenia was found to independently predict CDI-related mortality in these patients [24].

Cancer patients maintain a particularly high risk for CDI. Given their frequent or prolonged hospitalizations, patients may have a greater degree of exposure to C. difficile. Duration of hospital stay has been previously linked to CDI, as well as recurrent CDI [27, 28]. Prince et al. [29] reported that $32 \%$ of cancer patients undergoing chemotherapy had at least one hospitalization, and cancer inpatients have been found to have longer median LOS compared to non-cancer patients. In a retrospective study of inpatients, $36 \%$ of cancer patients were found to have LOS > 7 days compared to $26 \%$ of noncancer patients [30]. Schuller et al. [31] found that over the course of a year, $13 \%$ of patients on a pediatric oncology ward developed CDI. Analysis illustrated that duration of hospital stay was a primary determinant of infection, given patients' increased likelihood of intensive neutropenia treatment or long-term antibiotic exposure.
In 2009, NHDS data estimated that the average LOS for an adult primary cancer diagnosis was 1.6 days longer than a non-cancer diagnosis, with secondary malignancies, lung cancer, and prostate cancer leading in number of inpatient discharges [32].

CDI rates varied based upon cancer type. CDI was found to be over 2.5 times more common among patients with blood cancers compared to those with solid cancers. This disparity may be due to disproportionate CDI risk factors among blood cancer patients. First, patients with blood cancers might receive antibiotics at a higher rate due to a higher incidence of neutropenic fever resulting from cytotoxic chemotherapy and direct effects on host immunity [33]. Furthermore, patients with blood cancers tend to have a longer length of stay during hospitalizations compared to solid tumor patients [32]. Lastly, blood cancers have the therapeutic option of HSCT. When comparing HSCT recipients versus other cancer patients, Chopra et al. [5] reported HSCT recipients to have 1.4 times higher CDI rates. It is hypothesized these differences are due to chemotherapy regimens and antibiotic use leading up to transplantation, in addition to prolonged hospital stay $[6,34-36]$. The distinction between blood cancer versus solid cancer is of importance in CDI prevention and treatment. Due to the increased risk associated with hematologic malignancies, more diligent antimicrobial stewardship may be warranted along with potentially more aggressive CDI treatment.

Immunosuppression from host immunosenescence, the disease, or drug therapy could predispose cancer patients to clinical infection, rather than colonization, as the patient might not be able to mount as strong of a host response. Older age $[16,27]$, severe underlying disease [16, 27], and immunosuppressive therapy [37, 38] have all previously been associated with CDI. Furthermore, prior studies have shown that immunosuppressed patients who develop CDI are at higher risk for poor clinical outcomes $[5,6]$. 
Lastly, cancer patients are frequently exposed to medications and other factors that can alter the gut microbiota or alter the host response. The following classes of medications or therapies are used frequently among cancer patients and have been previously associated with CDI: antibiotics [16, 27, 37-39], certain chemotherapeutic agents [40], gastric acid suppressing medications [27], and manipulation of the gastrointestinal tract (e.g., enteral feedings, enemas, stimulants) [41].

Knowledge of the burden of CDI among cancer patients is important for several reasons. First, cancer patients can be more readily identified as a high-risk population in whom antimicrobial stewardship and other infection control processes should be targeted. Furthermore, clinicians might choose CDI therapy differently for cancer patients as compared to non-cancer patients. For example, clinicians might choose a more aggressive or costly therapy in cancer patients to improve clinical outcomes. A prior randomized controlled trial found that, among cancer patients, fidaxomicin use resulted in higher clinical cure rates and fewer recurrences as compared to those treated with vancomycin [42].

This study has limitations, predominately due to its retrospective design. First, use of ICD-9-CM codes to identify $\mathrm{CDI}$ and cancer diagnoses could result in misclassification bias, as these diagnoses could not be confirmed. However, a prior study noted relatively high sensitivity $(78 \%)$ and specificity (99.7\%) of the CDI ICD-9-CM code compared to microbiological data [43]. Additionally, data related to specific CDI diagnostic procedures were unavailable and could have affected incidence rates, as more sensitive detection methods (e.g., PCR) have been used more commonly in recent years. Lack of these diagnostic tests and other CDI-specific information precluded the analysis of specific $C$. difficile strains, presence of CDI on admission, and stratification by initial and recurrent CDI episodes. Factors that could have influenced CDI outcomes, but were unavailable to control for in analyses included: medications, other health care exposures, and severity of CDI or cancer. In the case of disease severity, patients with cancer or severe illness may suffer prolonged hospitalization or require additional medications, perhaps leading to increased mortality and LOS overall. Lastly, the NHDS include only community hospitals; therefore, our results might not be generalizable to federal or long-term care hospitals or outpatient facilities.

\section{Conclusions}

CDI incidence increased dramatically among adult cancer patients discharged from U.S. community hospitals between 2001 and 2010. Furthermore, CDI significantly increased the risk for mortality and prolonged hospital stays among cancer patients.

\section{Abbreviations}

CDI: Clostridium difficile infection; Cl: Confidence interval; HO-CDI: Hospitalonset Clostridium difficile infection; HSCT: Hematopoietic stem cell transplant; ICD-9-CM: International classification of diseases, 9th revision, clinical modifications; LOS: Length of stay; NAP1/BI/027: North American pulsed-field Type 1, with a restriction enzyme analysis type BI and PCR ribotype 027; NHDS: National hospital discharge survey; OR: Odds ratio; PCR: Polymerase chain reaction; US: United States

Acknowledgements

Not applicable.

\section{Funding}

No funding was provided for the conduct of this study. Dr. Reveles is supported by the National Institutes of Health/National Institute on Aging San Antonio Claude D. Pepper Older Americans Independence Center (1P30AG044271-01A1) Career Development (KL2) Program.

\section{Availability of data and materials}

The datasets supporting the conclusions of this article are available for public access through the Centers for Disease Control and Prevention, https:// www.cdc.gov/nchs/nhds/.

\section{Authors' contributions}

All authors participated in the design of the study. AD and KR performed statistical analyses. All authors participated in interpretation of the data. AD drafted the initial manuscript. FC, IR and KR revised the manuscript for intellectual content. All authors read and approved the final manuscript.

\section{Competing interests}

The authors declare that they have no competing interests.

Consent for publication

Not applicable.

Ethics approval and consent to participate

The datasets contain no patient identifying information; therefore, the Institutional Review Board of the University of Texas Health Science Center at San Antonio considered this study non-human subjects research.

\section{Publisher's Note}

Springer Nature remains neutral with regard to jurisdictional claims in published maps and institutional affiliations.

\section{Author details}

'College of Pharmacy, The University of Texas at Austin, 2409 University Avenue, A1900, Austin, TX 78712, USA. ${ }^{2}$ Pharmacotherapy Education and Research Center, The University of Texas Health Science Center at San Antonio, 7703 Floyd Curl Drive, MC-6220, San Antonio, TX 78229, USA.

${ }^{3}$ Cancer Therapy and Research Center, The University of Texas Health Science Center at San Antonio, 7979 Wurzbach Road, San Antonio, TX 78229, USA.

Received: 10 February 2017 Accepted: 15 June 2017

Published online: 23 June 2017

\section{References}

1. Magill SS, Edwards JR, Bamberg W, Beldavs ZG, Dumyati G, Kainer MA, et al. Multistate point-prevalence survey of health care-associated infections. New Engl J Med. 2014;370(13):1198-208.

2. Rupnik M, Wilcox MH, Gerding DN. Clostridium difficile infection: new developments in epidemiology and pathogenesis. Nat Rev Microbiol. 2009;7(7):526-36.

3. Reveles KR, Lee GC, Boyd NK, Frei CR. The rise in Clostridium difficile infection incidence among hospitalized adults in the United States: 2001-2010. Am J Inject Control. 2014;42(10):1028-32.

4. Kamboj M, Son C, Cantu S, Chemaly RF, Dickman J, Dubberke E, et al. Hospital-onset Clostridium difficile infection rates in persons with cancer or hematopoietic stem cell transplant: a C3IC network report. Infect Control Hosp Epidemiol. 2012;33(11):1162-5. 
5. Chopra T, Chandrasekar P, Salimnia H, Heilbrun L, Smith D, Alangaden G. Recent epidemiology of Clostridium difficile infection during hematopoietic stem cell transplantation. Clin Transpl. 2011;25(1):E82-7.

6. Alonso CD, Treadway SB, Hanna DB, Huff CA, Neofytos D, Carroll KC, et al. Epidemiology and outcomes of Clostridium difficile infections in hematopoietic stem cell transplant recipients. Clin Infect Dis. 2012;54(8):1053-63.

7. Britton RA, Young VB. Interaction between the intestinal microbiota and host in Clostridium difficile colonization resistance. Trends Microbiol. 2012;20(7):313-9.

8. Argamany JR, Aitken SL, Lee GC, Boyd NK, Reveles KR. Regional and seasonal variation in Clostridium difficile infections among hospitalized patients in the United States, 2001-2010. Am J Infect Control. 2015;43(5):435-40.

9. Reveles KR, Lee GC, Boyd NK, Frei CR. The rise in Clostridium difficile infection incidence among hospitalized adults in the United States: 2001-2010. Am J Infect Control. 2014;42(10):1028-32.

10. Lucado J, Gould C, Elixhauser A. Clostridium difficile infections (CDI) in hospital stays, 2009. HCUP Statistical Brief 124. January 2012. Rockville, MD: Agency for Healthcare Research and Quality. http://www.hcup-us.ahrq.gov/ reports/statbriefs/sb124.pdf. Accessed 27 Dec 2011.

11. Pepin J, Valiquette L, Alary ME, Villemure P, Pelletier A, Forget $K$, et al. Clostridium difficile-associated diarrhea in a region of Quebec from 1991 to 2003: a changing pattern of disease severity. CMAJ. 2004;171(5):466-72.

12. Loo VG, Poirier L, Miller MA, Oughton M, Libman MD, Michaud S, et al. A predominantly clonal multi-institutional outbreak of Clostridium difficileassociated diarrhea with high morbidity and mortality. N Engl J Med. 2005;353(23):2442-9.

13. Labbe AC, Poirier L, Maccannell D, Louie T, Savoie M, Beliveau C, et al. Clostridium difficile infections in a Canadian tertiary care hospital before and during a regional epidemic associated with the BI/NAP1/027 strain. Antimicrob Agents Chemother. 2008:52(9):3180-7.

14. Eggertson L. Quebec strain of C. difficile in 7 provinces. CMAJ. 2006;174(5):607-8.

15. Kuijper EJ, Coignard B, Tull P. Emergence of Clostridium difficileassociated disease in North America and Europe. Clin Microbiol Infect. 2006;12(Suppl 6):2-18

16. Bauer MP, Notermans DW, van Benthem BH, Brazier JS, Wilcox MH, Rupnik M, et al. Clostridium difficile infection in Europe: a hospital-based survey. Lancet. 2011;377(9759):63-73.

17. Gerding DN. Global epidemiology of Clostridium difficile infection in 2010. Infect Control Hosp Epidemiol. 2010;31(Suppl 1):S32-4

18. Kuijper EJ, Barbut F, Brazier JS, Kleinkauf N, Eckmanns T, Lambert ML, et al. Update of Clostridium difficile infection due to PCR ribotype 027 in Europe, 2008. Euro Surveill. 2008;13(31):1-7.

19. Goorhuis A, Bakker D, Corver J, Debast SB, Harmanus C, Notermans DW, et al Emergence of Clostridium difficile infection due to a new hypervirulent strain, polymerase chain reaction ribotype 078. Clin Infect Dis. 2008; 47(9):1162-70.

20. Gorschlüter M, Glasmacher A, Hahn C, Schakowski F, Ziske C, Molitor E, et al. Clostridium difficile infection in patients with neutropenia. Clin Infect Dis. 2001;33(6):786-91.

21. Schalk E, Bohr UR, Konig B, Scheinpflug K, Mohren M. Clostridium difficileassociated diarrhoea, a frequent complication in patients with acute myeloid leukaemia. Ann Hematol. 2010;89(1):9-14.

22. Campbell R, Dean B, Nathanson B, Haidar T, Strauss M, Thomas S. Length of stay and hospital costs among high-risk patients with hospital-origin Clostridium difficile-associated diarrhea. J Med Econ. 2013;16(3):440-8.

23. Stewart DB, Yacoub E, Zhu J. Chemotherapy patients with C. difficile colitis have outcomes similar to immunocompetent $C$. difficile patients. J Gastrointest Surg. 2012;16(8):1566-72.

24. Yoon YK, Kim MJ, Sohn JW, Kim HS, Choi YJ, Kim JS, et al. Predictors of mortality attributable to Clostridium difficile infection in patients with underlying malignancy. Support Care Cancer. 2014;22(8):2039-48.

25. Wang MS, Evans CT, Rodriguez T, Gerding DN, Johnson S. Clostridium difficile infection and limitations of markers for severity in patients with hematologic malignancy. Infect Control Hosp Epidemiol. 2013;34(2):127-32

26. Apostolopoulou E, Raftopoulos V, Terzis K, Elefsiniotis I. Infection probability score: a predictor of Clostridium difficile-associated disease onset in patients with haematological malignancy. Eur J Oncol Nurs. 2011;15(5):404-9.

27. Bignardi GE. Risk factors for Clostridium difficile infection. J Hosp Infect. 1998;40(1):1-15
28. Johnson S. Recurrent Clostridium difficile infection: a review of risk factors, treatments, and outcomes. J Inf Secur. 2009;58(6):403-10.

29. Prince RM, Krzyzanowska MK, Atenafu EG: Frequency and predictors of hospitalization during chemotherapy: a systematic review. J Clin Oncol. 2015;33:suppl;abstr 6583.

30. Suda KJ, Motl SE, Kuth JC. Inpatient oncology length of stay and hospital costs: implications for rising inpatient expenditures. J Appl Res. 2006;6(2):126-32.

31. Schuller I, Saha V, Lin L, Kingston J, Eden T, Tabaqchali S. Investigation and management of Clostridium difficile colonisation in a paediatric oncology unit. Arch Dis Child. 1995;72(3):219-22.

32. Healthcare Cost and Utilization Project. Cancer hospitalizations for adults, 2009. Available at: http://www.hcup-us.ahrq.gov/reports/statbriefs/sb125.pdf. Accessed 16 May 2017.

33. Jolis L, Carabantes F, Pernas S, Cantos B, Lopez A, Torres P, et al. Incidence of chemotherapy-induced neutropenia and current practice of prophylaxis with granulocyte colony-stimulating factors in cancer patients in Spain: a prospective, observational study. Eur J Cancer Care. 2013;22(4):513-21.

34. Anand A, Glatt AE. Clostridium difficile infection associated with antineoplastic chemotherapy: a review. Clin Infect Dis. 1993;17(1):109-13.

35. Agha A, Sehgal A, Lim MJ, Weber D, Hou JZ, Farah R, et al. Peri-transplant Clostridium difficile infections in patients undergoing allogeneic hematopoietic progenitor cell transplant. Am J Hematol. 2016;91(3):291-4.

36. Schilling MB, Parks C, Deeter RG. Costs and outcomes associated with hospitalized cancer patients with neutropenic complications: a retrospective study. Exp Ther Med. 2011;2(5):859-66.

37. Bilgrami S, Feingold JM, Dorsky D, Edwards RL, Bona RD, Khan AM, et al. Incidence and outcome of Clostridium difficile infection following autologous peripheral blood stem cell transplantation. Bone Marrow Transplant. 1999;23(10):1039-42.

38. Bartlett JG. The case for vancomycin as the preferred drug for treatment of Clostridium difficile infection. Clin Infect Dis. 2008;46(10):1489-92.

39. Barbut F, Corthier G, Charpak Y, Cerf M, Monteil H, Fosse T, et al. Prevalence and pathogenicity of Clostridium difficile in hospitalized patients. A French multicenter study. Arch Intern Med. 1996;156(13):1449-54.

40. Khan A, Raza S, Batul SA, Khan M, Aksoy T, Baig MA, et al. The evolution of Clostridium difficile infection in cancer patients: epidemiology, pathophysiology, and guidelines for prevention and management. Recent Pat Antiinfect Drug Discov. 2012;7(2):157-70

41. MCFarland LV, Surawicz CM, Stamm WE. Risk factors for Clostridium difficile carriage and C. difficile-associated diarrhea in a cohort of hospitalized patients. J Infect Dis. 1990;162(3):678-84.

42. Cornely OA, Miller MA, Fantin B, Mullane K, Kean Y, Gorbach S. Resolution of Clostridium difficile-associated diarrhea in patients with cancer treated with fidaxomicin or vancomycin. J Clin Oncol. 2013;31(19):2493-9.

43. Dubberke ER, Reske KA, McDonald LC, Fraser VJ. ICD-9 codes and surveillance for Clostridium difficile-associated disease. Emerg Infect Dis. 2006:12(10):1576-9.

\section{Submit your next manuscript to BioMed Central and we will help you at every step:}

- We accept pre-submission inquiries

- Our selector tool helps you to find the most relevant journal

- We provide round the clock customer support

- Convenient online submission

- Thorough peer review

- Inclusion in PubMed and all major indexing services

- Maximum visibility for your research

Submit your manuscript at www.biomedcentral.com/submit 